\title{
Cultura corporal de movimento em pauta: uma análise sobre o objeto de ensino da Educação Física como vetor dos processos de subjetivação com o corpo
}

\section{RESUMO}

Trata de um aspecto importante para a prática pedagógica da EF: a relação possível entre o ofício de professor e o objeto de ensino, após as reformulações nas propostas progressistas. A ideia de "cultura corporal de movimento" não resolve a contradição de tomar as práticas corporais como substrato da conscientização sobre a condição humana ou engendrar as práticas corporais como forma de resistir à dominação. Busca o conceito de práticas corporais para tensionar a ideia de que há um intercâmbio direto de sentido entre corpo e cultura. Para isso, analisamos como praticantes de Futebol Freestyle se organizavam quando a prática se destacava como algo diferente do futebol através da análise de um fórum, evidenciando processos de subjetivação; e analisamos obras que tratam especificamente do tema. Entendemos que as práticas corporais apresentam imanência material, o que pode ser um caminho para as práticas pedagógicas da EF.

PALAVRAS-CHAVE: Educação física e treinamento; Cultura; Movimento
Filipe Ferreira Ghidetti

Doutor em Educação

Universidade Federal de Santa Catarina -

UFSC

Programa de Pós-Graduação em Educação Florianópolis, Santa Catarina, Brasil

filipe ghidettil@hotmail.com

(1) https://orcid.org/0000-0003-4239-3036

Renata Marques Rodrigues

Doutoranda em Educação

Universidade Federal de Santa Catarina -

UFSC Programa de Pós-Graduação em

Educação

Florianópolis, Santa Catarina, Brasil renata.m.rodrigues@hotmail.com

[Dttps://orcid.org/0000-0002-9153-7238 
Body culture of movement in question: an analysis about the object of Physical Education as a vector of processes of subjectivation with the body

\begin{abstract}
It treats a important aspect for the teaching of Physical Education (PE): the possible relation between the office of teacher and the object of teaching, after reformulations in progressive proposals. The idea of "body culture" does not solve the contradiction between taking bodily practices as the substratum of awareness of the human condition and engendering bodily practices as a way of resisting domination. It seeks to question the concept of bodily practices to draw attention to the idea that there is a direct exchange of meaning between body and culture. To do this, we analyzed how Football Freestyle was organized when the practice stood out as something different than soccer through the analysis of a forum, showing processes of subjectivity; and we analyze also studies that specifically deal with the theme. We understand that bodily practices present material immanence, which can be a way for the pedagogical practices of PE.
\end{abstract}

KEYWORDS: Physical education and training; Culture; Movement

Cultura corporal de movimiento en pauta: un análisis sobre el objeto de enseñanza de la Educación Física como vector de los procesos de subjetivación con el cuerpo

\title{
RESUMEN
}

Examina un aspecto importante para la práctica pedagógica de EF: la relación posible entre el oficio de profesor y el objeto de enseñanza, tras las reformulaciones en las propuestas progresistas. La idea de "cultura corporal de movimiento" no resuelve la contradicción entre tomar las prácticas corporales como sustrato de la concientización sobre la condición humana y engendrar las prácticas corporales como forma de resistir a la dominación. Busca cuestionar el concepto de prácticas corporales para problematizar la idea de que hay un intercambio directo de sentido entre cuerpo y cultura. Para esto, analizamos cómo practicantes de Fútbol Freestyle se organizaban cuando la práctica se destacaba como algo diferente del fútbol a través del análisis de un foro, exponendo procesos de subjetivación; y analizamos obras que tratan específicamente del tema. Entendemos que las prácticas corporales presentan inmanencia material, lo que puede ser un camino para las prácticas pedagógicas de la EF.

PALABRAS-CLAVE: Educación y entrenamiento físico; Cultura; Movimiento 
"O homem se apropria da cultura corporal dispondo sua intencionalidade para o lúdico, o artístico, o agonístico, o estético ou outros, que são representações, idéias, conceitos produzidos pela consciência

social e que chamaremos de 'significações objetivas'. Em face delas, ele desenvolve um 'sentido pessoal' que exprime sua subjetividade e relaciona as significações objetivas com a realidade da sua própria vida, do seu mundo e das suas motivações" (COLETIVO DE AUTORES, 2012, p. 62).

\section{Do objeto de ensino da EF escolar e dos processos de subjetivação propostos a partir do movimento renovador}

"Cultura corporal de movimento" é tido como o conceito que sumariza o objeto de ensino (portanto, de pesquisa) do campo da EF escolar. Uma "herança" que remete ao debate epistemológico do campo da EF, e, também, à discussão de grande fôlego sobre a especificidade da EF escolar, a partir do movimento renovador da década de 1980. As duas propostas pedagógicas que condensam esse projeto surgiram no campo no início da década de 1990: a crítico-superadora, com o conceito de cultura corporal, e, a crítico-emancipatória, com o conceito de cultura de movimento. Bracht (1999) tenta justamente identificar, depois de quase uma década do surgimento dessas propostas, qual é o processo de constituição das teorias pedagógicas da EF e chega à conclusão de que as mesmas refletem a concepção de corpo da sociedade moderna e se posicionam de maneira crítica nesse sentido. O que parece latente é que o posicionamento crítico ante os processos de engendramento do corpo na sociedade moderna não estão tão claros senão não haveria o que discutir.

No Coletivo de Autores (2012) já está colocado o ideal da conscientização e autonomia: “[O livro] deve fornecer elementos teóricos para a assimilação consciente do conhecimento, de modo que possa auxiliar o professor a pensar autonomamente" (COLETIVO DE AUTORES, 2012, p. 19). Sabemos, portanto, que os processos de subjetivação aqui propostos referem-se tanto aos professores participantes do campo quanto aos alunos da disciplina escolar Educação Física. O que faz sentido uma vez que o objeto de ensino também deve ser entendido como objeto de pesquisa, neste caso, a cultura corporal. Uma reconfiguração do objeto é premente:

A metodologia aqui é entendida como uma das formas de apreensão do conhecimento específico da educação física, tratado a partir de uma visão de totalidade, onde sempre está presente o singular de cada tema da cultura corporal e o geral que é a expressão corporal como linguagem social e historicamente construida (COLETIVO DE AUTORES, 2012, p. 20, grifo nosso).

Já começa a se desenhar a estruturação da conscientização que parte do singular para o total. A narrativa que articula o singular com o total é conhecida e tem como cenário a sociedade de classes onde o "[...] movimento social se caracteriza, fundamentalmente, pela luta entre as classes 
sociais a fim de afirmarem seus interesses" (COLETIVO DE AUTORES, 2012, p. 25). O processo de subjetivação aqui proposto tem a marca da teleologia. Os interesses da classe trabalhadora são imediatos, se resumem à sobrevivência; os interesses da classe proprietária se resumem à acumular riquezas, garantir o poder para manter a posição, manutenção do status quo. Para isso desenvolve e veicula formas de consciência social, ideologia; veicula valores, ética e moral, como universais. Pelo discurso, veiculam hipocrisia e detém esse direito. Emulam os movimentos sociais e os anulam. Isso é importante no enquadramento de quaisquer outras linguagens que surjam. Tal narrativa é referenciada na obra pelo conceito gramsciano de hegemonia. Nesse sentido, a luta se direciona para a tomada da hegemonia pelas classes populares; essa é a "luta histórica", a tomada de uma hegemonia por outra. Como os interesses na sociedade capitalista são antagônicos, os sujeitos individuais são desprovidos de poder nesse cenário; na verdade, o discurso individualista também é ideológico neste registro. Uma pedagogia aqui é tida como “[...] a teoria e método que constrói os discursos, as explicações sobre a prática social e sobre a ação dos homens na sociedade, onde se dá a sua educação" (COLETIVO DE AUTORES, 2012, p. 26). E esta, em específico, "busca responder a determinados interesses de classe". Esse aspecto não é de menor importância para identificarmos o processo de subjetivação da proposta crítico-superadora, que vai desembocar numa concepção de corpo, o objeto específico da EF escolar, aqui a cultura corporal. O comprometimento com os interesses das camadas populares se materializaria em um currículo que colocaria frente a frente o conhecimento científico e o conhecimento trazido pelos alunos e, em uma nova síntese, que explicitaria as relações sociais antes veladas nas formas de domínio do corpo. A relevância de uma disciplina escolar depende do fato de o seu objeto de estudo ser importante para a compreensão da realidade externa por parte do aluno, de onde há de vir o senso de totalidade: "Busca situar a sua contribuição particular para explicação da realidade social e natural no nível do pensamento/reflexão do aluno" (COLETIVO DE AUTORES, 2012, p. 30). Portanto, a disputa pelo projeto de subjetivação se dá a nível da reflexão. A alegação é que o modelo de conhecimento mais aceito, a lógica formal, escamoteia as relações sociais de desigualdade, mas tudo deve finalizar, no quarto ciclo (no ensino médio), com a percepção das propriedades comuns e regulares dos objetos, compreensão científica.

Mas que mudanças do objeto específico estão tramadas aqui? Na tentativa de adequar a EF a esse caráter de disciplina escolar seria preciso rever os seus antigos modos. Na perspectiva da aptidão física há um alinhamento com os interesses da classe dominante. Apoia-se em fundamentos (principalmente biológicos) para educar o homem forte e ágil para disputar a livre concorrência capitalista: "[...] através da educação, adaptar o homem à sociedade, alienando-o da sua condição de 
sujeito histórico, capaz de interferir na transformação da mesma" (COLETIVO DE AUTORES, 2012, p. 37). Em oposição, a perspectiva da reflexão sobre a cultura corporal:

Busca desenvolver uma reflexão pedagógica sobre o acervo de formas de representação do mundo que o homem tem produzido no decorrer da história, exteriorizadas pela expressão corporal: jogos, danças, lutas, exercícios ginásticos, esporte, malabarismo, contorcionismo, mímica e outros, que podem ser identificados como formas de representação simbólica de realidades vividas pelo homem, historicamente criadas e culturalmente desenvolvidas (COLETIVO DE AUTORES, 2012, p. 39).

Práticas corporais como formas de representação simbólica da realidade vivida, por um lado. Por outro, alega-se que a cultura corporal refere-se também às conquistas do homem sobre a natureza a partir de suas relações, como ficar ereto, por exemplo. A corporalidade historicamente construída como resposta a estímulos e necessidades, localizada, portanto, em determinadas épocas históricas. Entre a dimensão simbólica e a material nenhuma lógica se erige e, ainda assim, o projeto de subjetivação está traçado: "Nesse sentido, o conhecimento é tratado de forma a ser retraçado desde sua origem ou gênese, a fim de possibilitar ao aluno a visão de historicidade, permitindo-lhe compreender-se enquanto sujeito histórico, capaz de interferir nos rumos de sua vida privada e da atividade social sistematizada" (COLETIVO DE AUTORES, 2012, p. 40). Um projeto ambicioso, de situar o indivíduo e o colocar à beira da mudança histórica, no qual o corpo é algo a ser decodificado, que expressa uma determinada dimensão da existência humana. A história que não é contada em sua totalidade, é contada a partir do substrato corporal. ${ }^{1} \mathrm{O}$ aspecto teleológico é chave para compreender o objeto específico da EF nesta teoria pedagógica, o conceito de cultura corporal - apesar de não ter sido elaborado como conceito. A teoria em questão coloca como especificidade do objeto a "expressão corporal como linguagem", mas para isso opõe um conflito irresolvido entre intencionalidade do homem individual e intencionalidade da sociedade, de onde se extrai que existem significações objetivas na cultura corporal que interpenetram a vida dos homens.

O fluxo de consciência a ser desenvolvido começa na origem das práticas corporais desvelando seu caráter histórico e as relações de poder impostas pelas classes dominantes; ${ }^{2}$ a busca é justamente por identificar o discurso que cada prática veicula: “A capoeira encerra em seus movimentos a luta de emancipação do negro no Brasil escravocrata. Em seu conjunto de gestos, a

\footnotetext{
${ }^{1}$ Entendemos que aqui se configura a reprodução de uma teoria da consciência (marxiana) - localizando o ofício da EF na superestrutura - sem uma teoria do inconsciente que justifique o status atribuído ao corpo, como algo expressivo, que permita compreender seus modos de (des)construção.

${ }^{2}$ É conhecida a crítica ao esporte pelo seu caráter ideológico, porque se trata de uma produção sociocultural que se submete aos códigos e significados atribuídos pela sociedade capitalista e reproduz as desigualdades sociais: "Por essa razão, pode ser considerado uma forma de controle social, pela adaptação do praticante aos valores e normas dominantes defendidos para a 'funcionalidade' e desenvolvimento da sociedade" (COLETIVO DE AUTORES, 2012, p. 70).
} 
capoeira expressa, de forma explícita, a 'voz' do oprimido na sua relação com o opressor" (COLETIVO DE AUTORES, 2012, p. 75). O discurso ideológico deve ser desvelado e desconstruído de um lado mas reforçado, por outro: "A Educação Física brasileira precisa, assim, resgatar a capoeira enquanto manifestação cultural, ou seja, trabalhar com a sua historicidade, não desencarná-la do movimento cultural e político que a gerou" (COLETIVO DE AUTORES, 2012, p. 75). A teleologia da teoria faz o fluxo de consciência consoante com a noção da totalidade, o fim esperado para a luta de classes. Na verdade, tudo aquilo que foi aqui referido como corporal ou como significação objetiva torna-se substrato dessa narrativa englobante. Só isso pode responder ao caráter genérico do conceito de cultura corporal e jogar a perspectiva em direção à subida para a superfície do ser consciente:

O sentido que se busca é a concretização de um projeto político-pedagógico articulado com um projeto histórico de interesse da classe trabalhadora. Projeto político-pedagógico que tem como eixo curricular a apreensão e interferência crítica e autonomia na realidade [...] $O$ conteúdo advém da cultura corporal $e$ é selecionado em função de sua relevância para o projeto pedagógico e histórico e em função de sua contemporaneidade (COLETIVO DE AUTORES, 2012, p. 110, grifo nosso).

Essa teoria almeja novos processos de subjetivação, mas não tem conceito de subjetividade. Isso se traduz no tratamento da técnica nas práticas corporais: "Sugere-se que o professor desenvolva abordagens diferenciadas para os jogos e modalidades esportivas a partir não do gesto técnico e sim do significado que os fundamentos desses jogos e modalidades possuem" (COLETIVO DE AUTORES, 2012, p. 85).

A outra proposta de pedagogia crítica que complementa o conceito de cultura corporal de movimento é a Crítico-Emancipatória ${ }^{3}$, de Elenor Kunz, com o conceito de cultura de movimento ocupando o lugar de objeto específico da EF escolar e que se configura como uma aposta no vitalismo e nos processos criativos pelo movimento humano, com base na fenomenologia. O que é importante destacar nessa proposta, e que se difere do Coletivo, é que aqui o corpo não aparece como substrato do processo de conscientização, porém, ainda partilha da crítica ao caráter ideológico do esporte e como essa manifestação, se não tratada, "colonizaria" a cultura de movimento do Brasil. Ou seja, através dela podemos ainda pensar em possibilidades formativas das

\footnotetext{
${ }^{3}$ Diante do espaço do artigo, não abordamos de forma ampla esta proposta, mas indicamos uma referência que aborda o que pontuamos. Em "Transformação didático pedagógica do esporte”, as reflexões de Kunz partem do esporte como objeto de ensino na Educação Física tratado como cópia irrefletida do esporte de rendimento, reproduzindo valores capitalistas de forma acrítica. Destaca-se seu interesse formativo ao pontuar: "O objeto de ensino da Educação Física é assim, não apenas o desenvolvimento das ações do esporte, mas propiciar a compreensão crítica das diferentes formas da encenação esportiva, os seus interesses e os seus problemas vinculados ao contexto sociopolítico" (KUNZ, 2006, p.73). Aqui, também, o gesto técnico se converte num gesto somente expressivo.
} 
práticas corporais. O que permanece como falta é a indicação de que a conformação de uma nova sociedade estaria diretamente atrelada a novas formas de lidar com corpo.

A EF entra na instituição escolar por uma afinidade com a tradição racionalista, que separa o corpo do intelecto com o intuito de influenciar diretamente o comportamento humano pelas ações sobre o corpo. De acordo com a tradição ocidental, o sujeito é razão e o corpo, objeto. Nesta visão paradigmática, o corpo é o que leva a alma a se enganar; o corpo teria assim um papel secundário, nenhum papel emancipatório ou subversivo. Nas teorias do conhecimento da modernidade, nas quais a episteme científica é prioritária, o corpo tem um papel perturbador. De acordo com essa cisão, no controle racional do mundo, a EF nasce desta tradição. Bracht (1999, p. 72) diz que o corpo sofre várias intervenções com a finalidade de adaptá-lo às exigências das formas sociais de organização da produção e da reprodução da vida, e, daí provém as concepções de corpo produtivo, corpo saudável, corpo deserotizado, corpo dócil: "O déficit de dignidade do corpo vinha de seu caráter secundário perante a força emancipatória do espírito ou da razão" (BRACHT, 1999, p. 72). E isso é mostrado na história da EF, sendo que esse é o contraponto comum das teorias pedagógicas da EF para proporem outros processos de subjetivação. Onde o comportamento pela consciência falha se faz necessário uma intervenção direta pelo corpo. ${ }^{4} \mathrm{E}$ a EF desempenha essa função social mesmo depois de seu período de esportivização; o esporte acaba substituindo a ginástica como técnica de controle do corpo e até como aparato ideológico que coloca em marcha o discurso da aptidão física e da capacitação individual para o rendimento na sociedade capitalista. Junto com o movimento renovador vem um ponto de inflexão para o campo: a crítica ao paradigma da aptidão física e da esportivização coloca em questão a função social da EF questionando o seu reprodutivismo, a promoção da adaptação do comportamento pela intervenção no corporal, principalmente com a incorporação das discussões pedagógicas das décadas de 1970 e 1980 com base na Sociologia e Filosofia da Educação de orientação marxista. ${ }^{5}$

González e Fensterseifer $(2009$; 2010) tentam, em dois textos, pensar uma saída para esta negação que parte do campo da EF quanto a sua função social. Abordam inicialmente o papel da escola na cultura até chegar à problematização do papel específico da EF no contrato social, que não poderia ser o reprodutivismo. Trata-se de uma abordagem muito interessante porque procura discutir a especificidade da EF na educação e na república. Nesse sentido, a escola só tem função

\footnotetext{
${ }^{4}$ Bracht (1999, p. 73) reconhece como nascimento da EF a união do saber-fazer militar e do saber científico e autoridade do saber médico para o controle do corpo: “[...] colaborar na construção de corpos saudáveis e dóceis, ou melhor, com uma educação estética (da sensibilidade) que permitisse uma adequada adaptação ao processo produtivo ou a uma perspectiva política nacionalista".

${ }^{5}$ González e Fensterseifer (2009, p. 11) entendem ser impossível voltar atrás depois desse ponto de inflexão: "Segundo nossa percepção, a inclusão dessas preocupações na área imprimiu uma mudança de tal magnitude que é possível comparar esse fenômeno a um ponto de inflexão na qual a trajetória da EF faz uma quebra definitiva com sua tradição legitimadora". A ruptura com a tradição significa, para eles, a ruptura com a lógica do "exercitar-se para".
} 
social pelo que se encontra fora dela: a cultura. O primeiro argumento diz que a função da escola é preparar para tecer outros sentidos na rede de significados que é a cultura, defendendo que o conteúdo das disciplinas são construções históricas. No entanto, limitam o relativismo do argumento anterior quando dizem que o trabalho escolar é movido pela desigualdade fundante entre professor e alunos, que é o conhecimento do panorama de constituição do mundo. Um fato que termina por justificar a existência da escola: a redução paulatina dessa desigualdade fundante. A escola aparece como fundante dos processos de subjetivação; trata-se de admitir que "o exercício desse poder como coerção deliberada é que nos constitui como humanos" (GONZÁLEZ; FENSTERSEIFER, 2009, p. 15). Só pelo rebelar-se contra a coecção primeira, que se faz por via do aprendizado, é que é possível criar o novo. Lembram da abordagem arendtiana da educação e da necessidade de assumir a responsabilidade pelo mundo ante às novas gerações. González e Fensterseifer (2009, p. 16) completam: “[...] deve-se tomar o sujeito como efeito de processos de subjetivação e a realidade como construção histórica". O que parece ser uma mudança substancial em relação à proposta crítico-superadora é a plasticidade dos sujeitos e do mundo que permite pensar numa educação emancipatória. O sujeito aqui é apresentado como fluído e também como constituinte; mas isso supõe um processo, que aparentemente deve ser comandado pelo professor de EF. Se por um lado há uma aposta no "caráter subversivo do educador", "como mestre da suspeita", há também uma aposta que esse agente possa dominar os processos de subjetivação que constituem o mundo. Essa solidez é a demanda da república por “instituições fortes”, que guardem as verdades históricas - conservando, claro, sua fragilidade - e atuem contra o "inflacionamento do eu”. A secularidade das instituições significa sempre a busca pelo que nos ultrapassa e ainda assim, nos é tangível. A conclusão que chegam é de que a escola enquanto instituição não tem como fugir tanto da reprodução:

Falando da escola como instituição, podemos concluir com Arendt (2002) que ela é fundamentalmente reprodutora (vale lembrar que é o Estado que a exige) e, podemos acrescentar, não há instituição que não o seja, uma vez que uma instituição cumpre um papel formador e só formamos porque temos uma forma que, real ou virtualmente, está preconcebida (GONZÁLEZ; FENSTERSEIFER, 2009, p. 17).

Essa ambiguidade do processo de subjetivação almejado na educação procura a desconstrução a partir do esclarecimento do mecanismo de reprodução pela escola com a tematização e desnaturalização. Como na psicanálise, a escola deveria tentar realizar “[...] Algo próximo à afirmação de Edward Said de que cabe à educação conduzir o aluno à perda de identidade para que, em um segundo momento, este a recupere, não mais como destino, mas como escolha” (GONZÁLEZ; FENSTERSEIFER, 2009, p. 18). Transmitir conteúdos culturais 
preparando para o debate público dos interesses comuns. A desconstrução e a reconstrução até chegar à "formas de representar o mundo mais defensáveis do que outras". Mas o que fica faltando na ambiguidade desse processo de subjetivação é o status do que é corporal, uma revisão do conceito de cultura corporal de movimento. Insistimos na questão do objeto porque é só aí que pode haver uma abertura nos processos de subjetivação pelos quais passarão professores e alunos de EF. Achamos que não há avanço em González e Fensterseifer (2009; 2010) quanto à isso porque: 1) os autores do texto individualizam a passagem da solidez para a fluidez, consideram que só o indivíduo será capaz de dar a resposta - o salto do "saber fazer" para o "saber sobre o fazer" - em cada prática e de forma contextualizada, o que significa que se dá após a intervenção da $\mathrm{EF}^{6}$; 2) não há revisão sobre o que há de corporal na cultura corporal de movimento. A não reflexão sobre o caráter ambíguo do corpo - que no Coletivo de Autores aparece muito rapidamente como dimensão simbólica e dimensão material - se traduz na tripla divisão que fazem do conceito "cultura corporal de movimento": a) as possibilidades do se movimentar, que se referem à possibilidades filogenéticas para se movimentar, a ideia de que "os seres humanos, no transcurso histórico, foram descobrindo/construindo possibilidades de usar seu corpo, as quais se acumularam como conhecimento cultural tácito nos diferentes grupos sociais" (GONZÁLEZ; FENSTERSEIFER, 2010, p. 14), rigorosamente o mesmo que uma "dimensão material do corpo" e que nunca passou pelo ofício do professor de EF; b) práticas já sistematizadas de lazer e saúde, que envolvem tanto conhecimentos da experiência quanto o saber conceitual, nada muito diferente do "nascimento" da EF retratado por Bracht (1999) com a união do saber-fazer militar e do saber científico da Medicina; c) estruturas e representações sociais que atravessam as práticas corporais de forma indireta, conceitos que estão na origem das práticas. Partem da ideia de que há uma pluralidade de formas de se perceber e representar o mundo, e, nesse sentido, é preciso sempre desconstruir. O que implica que a EF escolar deve dar conta dos conhecimentos ensinados nas instituições nãoescolares; colocar os sujeitos participantes nas bordas da cultura, na fronteira: o propósito da disciplina "[...] é oferecer aos alunos o que nessas instituições não encontrarão: a possibilidade de colocar em questão os sentidos hegemônicos que nelas predominam e que se apresentam como que 'esquecidos' da sua condição de uma possibilidade de sentido, entre outros" (GONZÁLEZ; FENTERSEIFER, 2010, p. 18). Mas, seria o corporal só o gatilho disparador do discurso plural? A hierarquia do argumento de González e Fensterseifer (2009; 2010), pensando primeiro o papel da escola nos processos de subjetivação, e, depois, tentando pensar o lugar do corporal, anuncia o

\footnotetext{
${ }^{6}$ A meta não é muito distinta do Coletivo de Autores: Formar "[...] indivíduos dotados de capacidade crítica em condições de agir autonomamente na esfera da cultura corporal de movimento" (GONZÁLEZ; FENSTERSEIFER, 2010, p. 12).
} 
mesmo como o motivo da desconstrução. Não teríamos que assumir daí que a linguagem corporal é do mesmo tipo que a linguagem discursiva?

Bracht (1999) diz algo parecido quando diz que há um movimento de recuperação da dignidade do corpo nos processos de aprendizagem, onde antes só havia o entendimento de que só o intelecto participava do processo. É interessante acompanhar a agenda colocada por Bracht às teorias pedagógicas da EF, há quase 20 anos. Bracht (1999, p. 81) diz que uma mudança efetiva no entendimento do movimento humano está “[...] na dependência da mudança do imaginário social sobre o corpo e as atividades corporais"; é isso que sugere o texto, que uma mudança da concepção de corpo no social pode ser a anunciação de movimentos sócio-históricos mais amplos, que é de interesse das pedagogias progressistas, que almejam uma sociedade alternativa. Mas, que verdade histórica é defendida pela instituição EF? Uma especificidade a surgir de fora - à espera da fluidez - ou um status de objetividade que permita pensar outros processos de subjetivação além da reprodução social a partir da imanência? Bracht (1999) aponta para a necessidade tanto de fazer uma leitura adequada da "política do corpo" quanto da "história do corpo". Ele questiona se uma nova visão de corpo está sendo gestada, uma visão que “[...] supere a visão moderna [...] que foi a base da EF moderna" (BRACHT, 1999, p. 84). A intenção do autor no texto não poderia ser mais clara: "Daí a importância de uma leitura adequada da realidade que possa se articular com um projeto alternativo realizável” (BRACHT, 1999, p. 85). Parece supor, portanto, novas concepções de corpo pré-existentes que motivem as mudanças sociais. No que se segue, recorremos diretamente a um exame histórico de uma prática corporal derivativa (do futebol) na análise do processo de subjetivação de uma comunidade de praticantes. Nosso argumento procura tensionar os seguintes aspectos até aqui expostos: a) que as práticas corporais possam ser reconvertidas em discurso revolucionário, consciência; b) que elas já têm sentido em si mesmas, já são sujeito; c) que as práticas corporais não são a abertura de uma outra visão social de corpo, ou outra sociedade, mas que são sempre resistência, em referência aos usos sociais do corpo. As práticas corporais são simbólicas e também materiais, mas a sua espessura (seu caráter crítico) provém de sua técnica específica.

\section{Futebol Freestyle (FF): processos de subjetivação na configuração de uma nova prática corporal}

Trazemos, agora, um exemplo que mostra possibilidades emancipatórias dos sujeitos na (re)invenção de práticas corporais. Escolhemos o FF porque se trata de uma manifestação cultural que transforma um esporte institucionalizado - os próprios praticantes tomam como origem as 
campanhas publicitárias de futebol que fazem uso das habilidades que aparecem nos treinos, como resto, e acabam não fazendo parte do jogo no campo a partir de jogadores como Maradona, Ronaldinho, Cristiano Ronaldo, entre outros - em outra prática corporal com referências à sociedade atual e à condição urbana, algo aproximado ao que seria o cume dos processos de subjetivação que a EF escolar busca empreender. Não é possível atestar a origem histórica desta prática, mas é possível compor uma constelação dos fatores que a fazem surgir; ou melhor, não é necessário reconstruir a sua origem porque há um registro documental que atesta sua dissonância em relação à sociedade contemporânea antes de ser "engolida" pelas instituições do Esporte e do mercado, por exemplo. O que tomaremos como registro documental foi realizado no ano 2008 e consiste no acompanhamento de um fórum de praticantes do FF, na época amadores, antes da esportivização da prática. Na condição de graduandos (penúltimo ano de formação) realizamos um trabalho sobre "cultura jovem" dentro de uma disciplina que discutia os aspectos teóricometodológicos das especificidades do ensino da EF no ensino médio. Para compreender esta "nova linguagem", o lugar onde encontramos este grupo foi o fórum "Freestyle:BR". ${ }^{7}$ O primeiro registro documental que fizemos, em 2008, mostrava um grupo experimental que desenvolvia a prática em conjunto, com os poucos novos membros sendo inseridos com o apoio dos membros mais experientes. É possível fazer um corte geracional e identificar o grupo; a partir de um tópico de Outubro de 2008 "Profiles/Melhores do Brasil": eram jovens nascidos entre 1990 e 1992, com exceção de um nascido em 1987, faixa etária de 18-20 anos, recém saídos do ensino médio; moradores de várias capitais brasileiras, de classe média. Independente da diferença de idade, os que em 2008 já eram os "melhores do Brasil" - o que não é prepotência uma vez que o capixaba Murilo Pitol tirou terceiro lugar no primeiro campeonato mundial, organizado pela Red Bull, em 2008; nas seletivas e nacionais, os que alcançavam lugar de destaque eram membros do fórum; em 2009, Arthur Mansilla “desbancou” Murilo na final nacional (os dois eram membros) - começaram a praticar por volta de 2006, ano do ápice da carreira de Ronaldinho Gaúcho, considerado um “embaixador do esporte". O perfil dos participantes (classe média/alta) do fórum se confirma pela relação com vestuário e os aportes materiais da prática: no mínimo o participante da comunidade necessitaria um par de chuteiras (não é permitido postar vídeos feitos descalço), uma câmera digital e um computador pessoal para editar os vídeos e a bola, claro. O fórum representa, a partir de suas fases, como a prática já foi balizada por um caráter comunitário. O movimento do fórum

\footnotetext{
${ }^{7} \mathrm{O}$ fórum fica ainda localizado no domínio http://freestylebr.team-forum.net e alguns dos tópicos são abertos e outros só são acessíveis para os membros (somos membros desde 2008 quando entramos em contato com o grupo para fazer a pesquisa); os fóruns são ferramentas comuns da rede mundial de computadores e servem para que os interessados em determinados temas tirem dúvidas entre si sobre quaisquer sub-temas através da abertura dos tópicos - sempre são organizados por moderadores.
} 
Freestyle:BR (FSBR), que basicamente se trata da abertura e fechamento de tópicos a partir do esgotamento dos seus temas, mostra o que era a prática corporal de 2006 à 2010. A estrutura inicial, pelo tamanho reduzido da comunidade, tinha como grande finalidade a troca de experiência entre os freestylers (FS), a inserção dos novos membros de forma a dirimir suas dúvidas e reduzir o isolamento que pressupõe a prática: a comunidade é importante para atenuar o fato de que o treino das tricks (manobras) é toda a prática - que tem como produto, os vídeos compilados com as tricks. Tópicos sobre equipamento (qual é o melhor tênis para se utilizar, qual é a bola adequada, melhores lugares para treinar) mostram como a prática tem uma certa objetividade que é testada pelos FS no uso da indumentária já existente para futsal e futebol de campo. As bolas são os melhores exemplos: à medida que vai se consolidando a linguagem específica do futebol freestyle (FF), com FS se tornando referências mundiais, inclusive nomeando as tricks (Palle, Skóra, Touzani) substituindo, por exemplo, outras referências como Ronaldinho - a "gramática" específica vai se delineando, as tricks vão sendo hierarquizadas e uma marca começa a fabricar bolas específicas de FF, com peso e texturas diferentes. A textura da bola é feita de jeans que aumenta a fricção com a bola ganhando em aderência; a bola é mais leve e menor também. No entanto, é com o uso dos materiais dos outros futebóis que a especificidade do FF vai se produzindo e isso se nota na troca de experiências no fórum. Nos primeiros anos de fórum é possível identificar a característica expressiva da prática também na sua consecução. Se o treino ${ }^{8}$ constitui praticamente todo o tempo do FF, em que o praticante está individualizado na tarefa de "parir" as manobras, fazer falar o seu corpo de uma forma que nunca foi tentada - e as dores desempenham o papel de mostrar a dificuldade desse esforço $0^{9}$ - a finalização em forma de vídeo situa a prática junto ao skateboard e ao parkour, tomando a cidade como cenário de expressão. Espaços urbanos, não destinados para as práticas, são cooptados para surfar a cidade com a bola nos pés: nesse momento não há disputa por um capital corporal e esportivo, o FF não havia entrado na agenda das grandes marcas e nem das instituições esportivas. Constituíam a rotina do FS os treinos em casa, a prática na rua (apesar de que esse comportamento vai diminuindo entre os integrantes do fórum com o passar dos anos) e a exposição com os vídeos na internet. O que leva um indivíduo civilizado a submeter-se a uma disciplina ainda não decodificada cientificamente e colocar seu corpo sob esse ofício que se mostra

\footnotetext{
${ }^{8} \mathrm{O}$ movimento inicial de abertura de operações no fórum em forma de tópicos sempre priorizou o espaço das “dicas", o “como fazer". Este movimento é justamente o que configura o FF como uma prática; porque outras pessoas querem continuar fazendo. Os veteranos muitas vezes não conseguem atingir o estágio de traduzir em palavras o "como fazer" e apenas incentivam a insistência no treino e a confiança no sucesso. Em um tópico de "Dicas" de 2008, um FS comenta: “Alguém me disse assim: 'Quem sabe, faz'. Demorei a entender, mas entendi. Só depois de fazer é que você começa a entender como fazer".

${ }^{9}$ Em um tópico aberto no ano de 2008, um participante relata uma internação por exaustão e os outros participantes desenvolvem uma discussão onde identificam algumas dores específicas provenientes das práticas, como nas panturrilhas e canela.
} 
fundamentalmente em imagem (os tutoriais são apenas imagens das tricks em slow-motion)? Tratase de uma linguagem que se abre justamente do lugar do indivíduo no esporte coletivo futebol, e, especificamente, no Brasil, do mito do futebol criativo e da figura do malandro, que encontramos retratado em Wisnik (2008). A característica elíptica do futebol brasileiro em comparação com a ênfase prosaica do futebol europeu, explorada por Wisnik (2008), coloca o drible e as habilidades individuais (skills) em perspectiva porque podem ser a resolução total das tensões entre as forças atuantes no jogo de futebol ou pode ser simples devaneio, porque podem resultar em nada e prejudicar todo o esforço coletivo de construção e busca do gol. Por isso, a criação de novas habilidades individuais de trato com a bola no futebol (com peito, ombros, cabeça, tronco, coxas, canelas, panturrilhas, pés, solas e parte externa, ou seja, todo o corpo menos os braços) nos momentos de treino acabam servindo de substrato para o discurso mercadológico e esportivo, e, esse discurso transformado em imagem acaba se consolidando em uma prática corporal específica (FF). O indivíduo protagonista dessa nova prática - em muitos casos, moradores de apartamento -, com surgimento situado no início do séc. XXI, era municiado, na época, tanto por games (como o FIFA, mas também o FIFA Street de 2005, por exemplo, que simula um jogo de rua com as mesmas skills que vão dar origem ao FF) quanto por uma grade generosa das emissoras esportivas de TV à cabo que começavam a popularizar os grandes campeonatos europeus de futebol. O salto que leva das imagens de skills "mitológicas" às verdadeiras tricks resultantes de uma nova disciplina corporal é o que nos interessa. Nesse sentido, é interessante observar como eles se diferenciam dos boleiros, fato incluído até no estatuto do fórum (onde a linguagem boleira é proibida), figuras que destacam justamente a mitologia da onipotência do craque no jogo de futebol. Se submeter a novos usos do corpo é o mandatório nesse caso; a principal função do fórum é consolidar uma comunidade que estabelece um saber coletivo que suporte essa disciplina a que se submete o indivíduo; a projeção de um novo lugar para o indivíduo dentro desse esporte, que era coletivo.

Esse é o grande processo de subjetivação, neste caso. Destaca-se justamente o administrador do fórum. Ele não era um dos FS que disputaram os campeonatos nacionais e mundiais - em uma oportunidade chegou a se inscrever na Challenge Cup ${ }^{10}$ na categoria de Iniciantes - e sempre foi reconhecido pelos outros usuários do fórum como um exímio administrador. Este e o fórum seriam "quase" a mesma pessoa: ele planeja os logos, determinou quem pôde usá-lo, organizou os campeonatos e foi juiz dos mesmos. Nestes mesmos campeonatos, elaborou as regras e angariou "gringos" para participar dos campeonatos (a participação era por vídeo) se comunicando em inglês com os mesmos; a ação tinha como objetivo internacionalizar o fórum. Esse campeonato dá a

\footnotetext{
${ }^{10}$ Foi um dos primeiros campeonatos organizado entre os participantes do fórum.
} 
medida do que é a função do administrador do fórum na gestão das práticas de FF pela comunidade do fórum. O que é principal para o administrador era saber o que poderia esperar da comunidade do fórum, dos praticantes. Se, pela organização inicial ele consegue animar os praticantes a se desenvolverem e evoluir na prática - enuncia ser o principal objetivo do campeonato - as ações de organização são também as responsáveis pela falência da disputa. Os desafios são em divisões por níveis dos praticantes (Iniciantes, Intermediários, Avançados e Profissionais) e as tricks também são divididas por esses níveis: um desafiante realiza uma combinação de tricks e descreve outro conjunto de manobras a serem realizadas. Sempre é permitido que se insira tricks de um nível acima. Se o desafio é de iniciante é permitido inserir no combo uma trick do nível intermediário. O campeonato sucumbe porque os participantes não conseguem mais realizar os combos e desistem do mesmo. Mas, não se trata de um administrador centralizador; dá importância para as funções de divisão e de hierarquização dos tópicos no intuito de esgotar os problemas e temas que abrem a necessidade de um determinado tópico. Sempre há espaços de discussão e decisão de quase todos os temas pela comunidade, mas é a descentralização das ações do administrador, que ele mesmo empreende, que mostra a importância da função administrativa da FSBR no desenvolvimento da prática. Funções são delegadas de acordo com a especialidade de alguns participantes. Por exemplo, em um tópico em que o objetivo é que os usuários aprendam a editar vídeos (e aprender a manusear os softwares de edição de vídeos em suas diversas funções), um usuário especialista é chamado a organizar o fórum; ações desse tipo são comuns. $\mathrm{O}$ acontecimento que demonstra a importância da função administrativa do fórum para o $\mathrm{FF}^{11}$ é a reformulação projetada pelo administrador em 2010, que diante de sua ausência e confusão de mensagens no fórum sugere a volta da comunidade ao Orkut. Todos reconhecem a desorganização do fórum, mas, também, a maior multiplicidade de recursos do fórum, justificando a permanência da FSBR, contanto que fosse reorganizado: o objetivo principal dessa medida sempre foi reduzir a quantidade de tópicos - ou seja, a reconstrução tem como objetivo diminuir os esforços de inteligência da prática que não são frutíferos, limpar as operações, simplificar - para retomar a evolução da comunidade no $\mathrm{FF}^{12}$, sempre almejando a

\footnotetext{
${ }^{11}$ Em 27/07/2009, o administrador descobre que o fórum tem mais tópicos off topic do que tópicos sobre FF. Ele age viabilizando a evolução do fórum, tornando-o mais funcional para a prática do FF possibilitando a "antiga" troca de ideias. O administrador sugere, por exemplo, que todos os vídeos de FF postados no site tenham ficha técnica contendo o nível do FS, estilo e outros dados descritivos para explicitar o que está sendo apresentado porque isso ajudaria a "localizar qual é e como é a sugestão a ser dada visando a evolução" (sic). No sistema de reputação, o usuário ganha pontuação por ter dado uma boa dica de FF.

${ }^{12}$ A noção de objetividade da prática corporal FF aparece em duas oportunidades: 1) quando a linguagem específica do FF já é reconhecida por volta de 2008, os atletas planejam combos a serem realizados (portanto, que ainda não realizam), ou seja, as tricks são estágios de objetividade a serem atingidos; 2) no campeonato Unedited Cup (2008), que conta com a participação dos "gringos", os praticantes discutem as decisões dos jurados baseado no caráter objetivo das performances dos outros: julgam pela noção de "atleta completo" que é aquele que domina a maior variedade de tricks em seus tipos - sit down, upper, lower, ground. Um outro usuário contesta esse critério porque entende que "se
} 
esportivização e a profissionalização. Os tópicos são operações que levam à inteligência da prática, mas que acabam em um primeiro momento em desarticulação de seus papéis sociais - estruturar um ofício que não só não ajuda, mas atrapalha as atividades diárias de um adolescente de classe média em escolarização (alguns campeonatos “esfriaram” em períodos de férias porque a grande maioria estava viajando); muitos relatam a interrupção dos treinos pelas notas baixas na escola e pressão da família - mas que depois do primeiro campeonato mundial organizado pela Red Bull, passam a alimentar o ideal da profissionalização e capitalização dos esforços. ${ }^{13}$ A mentalidade que se construiu coletivamente às voltas com uma nova linguagem, ${ }^{14}$ - a prática corporal - que passeia entre a expressão linguística marginal dos rappers ou uma linguagem "precarizada" que deforma a língua portuguesa só por diversão (“Amanham”, “Ancioso”) e o inglês gramaticalmente correto, por mais de uma vez se repreendem entre si por erros no inglês diante dos "gringos" - aspira finalmente à integração. Além de muitos membros do fórum terem participado dos campeonatos da Red Bull, a própria comunidade tende a pressionar para a exclusividade; esse é o resultado da reformulação de 2010. A tendência é a conclusão de um FSBR Team, que começa lá atrás com a pergunta sobre a necessidade de contas VIP's e a capitalização da prática com a confecção de produtos específicos da FSBR. Esses eventos do fórum expressam na verdade o destino da prática corporal que nasceu como manifestação de um novo comportamento e rapidamente - num período curto de 2005 a 2008 - se transformou em um esporte e desejo do mercado publicitário. ${ }^{15}$

\section{CONSIDERAÇÕES FINAIS SOBRE OS PROCESSOS DE SUBJETIVAÇÃO EM EF}

Quem somos nós e o que podemos, professores de EF na escola, nesse processo acima descrito e que se repete? Processo que mostra que o caráter histórico/sociológico da prática preenche o vago conceito de prática corporal. Wisnik (2008) mostra como também a origem do

\footnotetext{
FREESTYLE fosse ser completo não seria LIVRE! No FF você faz o que você quer fazer e não o que os outros querem que você faça". O administrador nutre até um senso de progressividade, quando nega por mais de uma vez a retomada da discussão sobre se os campeonatos deveriam ser divididos em níveis alegando que se trata de um tema esgotado no passado. Por fim, acaba cedendo à pressão dos iniciantes que querem disputar entre si.

${ }^{13}$ A perspectiva de esportivização e profissionalização legitima uma atividade que antes "atrapalhava". Um exemplo: é estabelecido que a Unedited Cup, outro campeonato interno ao fórum, teria como critério a criação de vídeos não editados porque isso seria uma forma de testar como teria sido participar da Red Bull Street Style (primeira competição importante no FF).

${ }^{14}$ Em 2009 surge dos usuários o desejo de fazer uma "Bíblia do FF", uma espécie de dicionário que, diferente do tutorial que só separa as tricks em sua tipologia e as mostra por vídeos em slow motion, teria descrição verbal das manobras e tips (dicas) exclusivas para a elaboração das tricks. Tudo isso com o objetivo de tornar a modalidade reconhecida a partir de sua especificidade. Nessa oportunidade, um usuário comenta que o FS Michryc seria um desafio para o dicionário, porque este faz tricks desconhecidas.

${ }^{15}$ Em abril de 2008, uma empresária entra no fórum procurando um FS para um "bico", contanto que o contratado fosse morador de SP e maior de idade. O administrador a contesta dizendo não haver ninguém maior de idade no fórum.
} 
futebol é incerta, mas que a Inglaterra da alvorada do séc. XX é cenário decisivo para conformação da prática tal qual é até hoje. Um jogo cujo os traços expressavam o engendramento de uma nova sensibilidade: a construção do homem do novo século, capaz de respeitar as regras do novo jogo social, adaptado aos modos de competir e aos meios da sociedade industrializada, o gentleman. Uma prática dos estudantes ingleses - que chegou a ser proibida pelo rei por ser um esporte nãocristão - acabaria sendo institucionalizada como esporte mais à frente, processo que se desenvolveu e já dura mais de um século até chegarmos ao FF. Em “Entre o passado e o futuro", Hannah Arendt discute o tema da utopia para a Educação e problematiza as intenções utópicas do educador porque há sempre a possibilidade, neste caso, de que as possibilidades de construção do futuro sejam anuladas para a nova geração. A escola, enquanto instituição responsável pelo diálogo geracional não pode tratar o novo como se esse já existisse. Cada geração é como um mundo antigo e preparar uma nova geração para um mundo novo não pode ser arrancar dos recém-chegados suas possibilidades ante ao novo. Por outro lado, as instituições educacionais são as únicas responsáveis por tal diálogo geracional, e, como Arendt mesmo lembra, são guiadas pelo princípio da natalidade que diz que já há um mundo antes da chegada do novo que deve ser protegido. A condução ao nãolugar, a ser preenchido pelos novos, só pode se dar pela história. A arte, por exemplo, lida com a utopia, mas não de forma normativa. Uma nova sociedade esboçada a partir dessas novas práticas corporais, como FF, apresentam possiblidades formativas, porém, não seria e nem poderia ser a realização da utopia.

Wacquant (2002) num estudo etnográfico e sociológico, identifica como o Boxe se amalgama numa periferia de Chicago como prática ascética do jovem homem negro com valores que catalisam a possibilidade de inserção no mundo capitalista. $\mathrm{O}$ aspecto doutrinário não é de todo leve; o controle técnico das práticas do gym é todo incorporado pelo coach DeeDee, não havendo meios de dar vazão a esse saber senão pela submissão cega do boxeador aos códigos e disciplina impostos. As práticas corporais são secularização do trato com o corpo. Trust the process é um código do gym que traduz esse aspecto: esquemas que vão ao limite da linguagem e da racionalidade científica e propõem novos tratos com o corpo - experiências ainda não decodificadas pelas ciências médicas; determinadas práticas inclusive já foram proibidas por lei - rompem com sistemas de crença. Se consideramos que se trata da intervenção direta no principal substrato da civilização, o corpo, conseguimos dimensionar que tamanho tem essa intervenção. No caso da experiência retratada por Wacquant, há uma organização e uma economia das energias e dos esforços que, ao mesmo tempo que é simbiose com o entorno social, é, também, oposição às relações do bairro. Se trata, de fato, de uma pesquisa interessante e que poderia acrescentar na discussão do conceito cultura corporal de movimento: Löic Wacquant buscava um meio de se 
inserir no bairro para iniciar uma pesquisa sociológica e acabou sendo cooptado, inclusive alterando o foco da pesquisa para discutir diretamente o boxe. A secularização das práticas é rompimento com sistemas de crença e, como intervém diretamente no substrato da civilização, a instituição esportiva consegue deslocar melhor o foco, conformar o comportamento (junto com mercado e mídia) sob o discurso da saúde e a ideologia do rendimento. Mas, a intensa experiência de Wacquant com o boxe e a descrição exaustiva de cada minúcia da mesma, mostra a característica de prática corporal dentro do contexto esportivo do boxe. E o que ele mesmo diz é que é impossível elucidar o significado do boxe na sociedade sem a inserção no gym e a compreensão de suas relações simbólicas e sociais; refere-se diretamente ao imagético veiculado pelo cinema quanto à narrativa épica que define o imaginário sobre o boxe. O gym, o salão de treinamento é como a "fábrica do pugilista", ${ }^{16}$ onde se forja o mesmo a partir de um saber-fazer coletivo. O autor ressalta que a crença coletiva nutre relação íntima com os valores indígenas. Se há a função técnica latente do gym de transmitir uma competência esportiva, há também a função extrapugilística de desbanalizar a vida cotidiana e fornecer o acesso a um universo distintivo, a partir, é claro, da rotina e da remodelagem corporal. Esse desvio no "fluxo social" do gueto é muito menos épico: o boxe funciona como regulador da violência. Define, de quebra, o que seria prática corporal, como condutas produzidas aquém da consciência. Ainda que não haja teoria de ensino do boxe, há razão que a baseia; algo mais do que necessário devido ao fato de que se trata de um processo que coloca em risco o corpo individual, mas a partir de uma aprendizagem inteiramente coletiva. Mecanismos corporais e mentais são indistintos no ofício do boxer. O nexo com a cultura, a afiliação ao salão de boxe só faz sentido se compreendidas as oportunidades de vida e trabalho recusadas ou oferecidas, quanto à reprodução ou à mobilidade social. Woodlawn, onde fica o gym, era um bairro branco e próspero até que a imigração de negros das zonas rurais do sul tornou o bairro em decadente. No censo dos anos 80, um terço das famílias do bairro de Chicago viviam abaixo do nível federal de pobreza. As escolas do bairro eram "garantia de miséria e criminalidade". As instituições dominantes eram as igrejas e os botequins, e, claro, a criminalidade o destino principal dos jovens negros. A violência "estritamente policiada" do boxe empalidecia ante a proximidade dos sujeitos à violência diária. $\mathrm{O}$ clube se tornava uma ilha de ordem e estabilidade dentro desse cenário e possibilitava as relações sociais proibidas no exterior; o cenário claustrofóbico do gym ratifica isso, os usuários nutrem aí uma certa claustrofilia. Os tempos e eventos exteriores não tinham muita repercussão no interior; por exemplo, quando haviam eleições o assunto ficava do lado de fora. A epígrafe que abre o livro,

\footnotetext{
${ }^{16}$ Essa metáfora utilizada por Wacquant (2002), na medida em que traduz o fato de que o corpo é liberado das relações de produção, também mostra que há uma equivalente carga de trabalho que forja o pugilista. Movimentar-se aqui é estar lançado, uma vez que não há controle imediato no resultado do esforço laboral.
} 
"Nihil humanum alienum est", uma citação de Baruch Spinoza, dá o tom de que Wacquant (2002) viu na prática corporal do boxe no gym de DeeDee, em Woodlawn, que os processos de socialização ali empreendidos têm fim em si mesmos, não tem conteúdo específico. $O$ único assunto externo, que tem mesmo capital que o conhecimento pugilístico, é a violência das ruas e a cultura da rua no gueto. Trata-se do compartilhamento do mesmo contexto entre os pares que colocam o gym e o boxe como resposta possível ao contexto. É nesse sentido que ele diz que os boxeadores participantes geralmente saem da classe operária local que, diferente das "frações mais deserdadas do subproletariado do gueto", tem já uma inclinação pela vida regrada, "sentido de disciplina", enfim, o senso moral da integração na sociedade; têm uma espécie de formação mínima. Eis o que Wacquant (2002) descobre quanto ao processo de secularização do trato com o corpo, que o gym tem que se estabelecer como "instituição" quase total, que regula quase todos os aspectos da existência do boxeador; gestão de tempo/espaço, corpo, estado de espírito e desejo. Ainda que exista contiguidade entre o gueto e o gym, essa relação se rompe pela disciplina pugilística. A ordem do gym faz referência à desordem do exterior, mas é específica. Regulação individual e coletiva das paixões versus anarquia privada e pública; é controle do outcome da violência. $\mathrm{O}$ próprio da prática é uma lógica que se efetua diretamente na ginástica corporal. O que é aprendido no gym se inscreve na fronteira do dizível e do inteligível. A cultura do boxeador não é uma gama de modelos fechados, significados. Mas um “[...] complexo difuso de posições e de gestos que, continuamente reproduzidos [...] só existem em atos" (WACQUANT, 2002, p. 78). Nesse sentido a educação do corpo aqui efetuada trata-se de substituir o corpo selvagem pelo corpo acostumado com outros tempos. O boxe aqui é tido como ofício manual qualificado e repetitivo. A ascese do treinamento coloca o mesmo como trabalho e o corpo como instrumento; os gestos que aparentam ser simples e naturais, exigem uma intensa reeducação física que é saber exatamente como usar o corpo no momento oportuno. Wacquant (2002, p. 89) insiste: "De fato, há uma compreensão do corpo que ultrapassa - e precede - a plena compreensão visual e mental". De sua primeira luta no sparring, Wacquant destaca a impossibilidade de traduzir em palavra - "três minutos de desconhecido" - e agradece pela "surra", pelo estabelecimento da crença no ofício, na verdade do mesmo, da preparação do corpo boxeador.

A experiência do sparring foi também, para Wacquant, o disparador de algumas importantes reflexões feitas por ele sobre a prática corporal. A lógica social do sparring, que é recompensa e teste ao mesmo tempo, é abandono individual e controle coletivo; um ponto crucial da fabricação do pugilista. A lógica da escolha do parceiro de sparring é de que ambos tirem proveito do mesmo para evoluir. A violência controlada tem o objetivo de manter o equilíbrio entre os pugilistas que são instigados a levar uns aos outros ao limite. O técnico, por exemplo, deve garantir que não 
aconteça de que "[...] o combatente menos aguerrido seja brutalmente reduzido ao silêncio" (WACQUANT, 2002, p. 103). Por outro lado, ele tem que garantir que a intensidade dos golpes não baixe muito em relação ao que será encontrado pelos boxeadores na luta. Nesse sentido, o autor entende que o sparring promove o aprendizado porque se trata de levar o parceiro ao limite e de trazer esse limite à tona no ringue, mostrar. Só assim a prática vai contra o princípio público da competição desenfreada. Mas, o principal com relação ao sparring é a mudança na percepção; tratase da educação dos sentidos, das faculdades visuais, com a transformação da estrutura e da extensão do campo visual. Wacquant ratifica que o sparring é uma outra paisagem cognitiva que se apresenta e demanda o vetor que deve organizá-la. A partir do treinamento coletivo se consegue recriar essa paisagem com a demanda de outro vetor. O envolvimento no sparring demanda uma presença corporal total que esconde a imbricação entre gesto, experiência consciente e processo fisiológico: "Não conseguir dominar a experiência sensorial dos golpes que caem sobre você amputa a capacidade de agir e altera, em contrapartida, o estado corporal" (WACQUANT, 2002, p. 114). No boxe, trata-se mais de receber os golpes do que dá-los; trata-se de modificar o esquema corporal, o uso que habitualmente fazemos dele e interiorizar uma série de disposições inseparavelmente mentais e físicas. E aqui um argumento ousado: Wacquant entende que as lutas beiram à inconsciência porque são territórios não-testados que podem levar até mesmo à morte (por isso há a avaliação tácita de "jogar a toalha" para parar as lutas). O autor responde que essa zona de indistinção entre o corporal e o mental - body-mind complex - vem do saber-fazer coletivo: "Essa capacidade de pensar vem da razão prática incrustrada no fundo de um corpo. Escapa à lógica da escolha individual" (WACQUANT, 2002, p. 118). As decisões tomadas no ringue são tomadas por dentro de uma sensibilidade pugilística incorporada; em alguma medida, o corpo é o sujeito aqui, porque forjado coletivamente. Não há atribuição de primordialidade a nenhum dos fatores presentes na cena para compreendê-la previamente à ação: a decisão é a ação.

Trata-se de uma pedagogia implícita e coletiva, uma prática corporal pouco codificada que se aprende por inculcação prática e coletiva, é a "manipulação regrada do corpo que somatiza o saber coletivamente detido". O gym está para o boxe assim como a igreja está para a religião; uma comunidade moral, um "sistema solidário de crenças e práticas” é o que constitui essas instituições. Wacquant relata a aversão de DeeDee (o técnico) quanto à sistematização do aprendizado do boxe em livros porque "o que o treinador denuncia nos escritos é seu efeito de totalização e destemporalização" (WACQUANT, 2002, p. 122). Boxe é jogado no tempo e joga estrategicamente com o tempo; é não-etapista, diferente das outras lutas. Não se sobe estágios de uma vez por todas, o pugilista top é aquele que mantém a deformação de seu corpo - tal qual uma máquina de dar e receber socos - contra os efeitos do tempo. Não há como decompor os gestos porque um gesto 
tecnicamente perfeito não é nada fora do que é o corpo no ringue: o feixe dentro do fluxo da luta, o que destitui o gesto de valor se não ancorado no "andamento da troca" e no "estilo do boxeador". A rejeição do academicismo e da ciência tem um aspecto moral de que não há atalhos em direção a estar pronto para boxear senão a partir da disciplina individual e a submissão. Nesse sentido, o modo de fazer coletivo em que o corpo é acostumado ao ritmo do gym - o mesmo da luta, 3 minutos de combate e 1 de descanso - e, também, de um saber prático que roda entre os participantes do gym - a correção é sempre coletiva e há também a necessidade de lutadores profissionais que descentralizam o saber-fazer de DeeDee - levam a esse senso de capital corporal e da gestão do mesmo. Instrumento de trabalho e alvo para o adversário, inspira o senso prático de poupança que vem da sua construção no gym. "Ao orquestrar as múltiplas ações que, imbricandose, definam o gym como configuração móvel de agentes interdependentes, DeeDee contribui para produzir e cristalizar a crença pugilística” (WACQUANT, 2002, p. 170, grifo nosso).

Nossa intenção era expor o impasse teórico presente na ideia de "cultura corporal". Isso se dá devido à separação entre as dimensões simbólica e material. A herança das pedagogias progressistas brasileiras e o ideal de quebrar com a reprodução social pela escola levam à crítica ao esporte competitivo e ao seu consequente caráter reprodutivo. No entanto, é a insistência nessa lógica (práticas corporais reproduzindo um modelo de sociedade) - e a tentativa de reconvertê-la ao lado certo da história - que impede que avancemos porque coloca as práticas corporais e o corpo como substrato da mudança social. O silêncio sobre a relação entre as dimensões simbólica e material também precisaria ser superado, assim como a substancialização do corpo que ocorre ao enquadrá-lo como outro patamar de linguagem. É nesse sentido que o FF se mostrou uma recontextualização das possibilidades do futebol (e do corpo). Assim como o skate urbano (CORNEJO AMÉSTICA et al., 2006), que é identificado neste contexto como oposição contra o sistema formal e tradicional de diversão, o FF se equiparou às práticas urbanas que têm como características: a) o nomadismo, devido ao caráter de exclusividade da configuração dos espaços urbanos; b) a adaptação material, ressignificando os próprios espaços; e c) a invenção de códigos e regras próprios. Os praticantes se organizam em grupos e territorialmente, mas o que se destaca é o processo identitário em formação com posicionamento espacial (que é a apropriação simbólica de um espaço físico), posicionamento relacional (que destaca um modo particular de conexão com o mundo externo) e posicionamento temporal (apropriação de uma parte da história, procurando assegurar continuidade temporal e visualizando "algo" que possa satisfazer o tempo existencial). A identidade seria o conjunto de operações mentais próprio da tomada de controle do espaço e do tempo. Trata-se de uma investida contra a cultura esportiva e urbana que é o que registramos naquela comunidade de FF e que logo foi dissolvido com a esportivização. 
As práticas corporais têm essa característica da imanência, retomam essa parte da história que é o domínio material. É pela exploração direta do que pode o corpo, do que o retira da condição de corpo integrante da massa social, das relações de produção. É esse contraste que expõe completamente o domínio das forças vitais a que era exposto o corpo. O fórum, o gym e a tribo callejera são as instituições necessárias (e possíveis) para garantir ao corpo individual essa possibilidade da resistência à lógica da fungibilidade. Esse processo que estamos relatando não garante, por si só, a participação individual. A arte também recria um topos que pode motivar o conhecimento. A zona gris entre as dimensões simbólica e material é desencadeada por novos processos de subjetivação que buscam uma espécie de desarticulação; é da ordem do sujeito porque interfere diretamente na objetividade e desarticula uma subjetividade anterior. Vejamos o exemplo da arte: “[...] quanto mais a emancipação do sujeito demole todas as representações de uma ordem pré-dada e doadora de sentido, tanto mais problemático se torna o conceito de sentido como refúgio da teologia declinante" (Adorno, 2013, p. 223). A arte resolve esse impasse uma vez que a emancipação da obra de arte da necessidade de fazer sentido acontece quando a obra se torna rica de sentido ao retomar a história no material estético. O FF é uma nova prática corporal que se erigiu da técnica futebolística (de seu resto) se ancorando em significados sociais progressistas, mas que logo foi diluída em lógicas pré-existentes e prementes do mundo capitalista. Antes de desaparecer, mostrou o corpo em febre. ${ }^{17}$

\section{REFERÊNCIAS}

ADORNO, Theodor Wiesengrund. Teoria Estética. Lisboa: Edições 70, 2013.

AMÉSTICA, Miguel Cornejo et al. El skate urbano juvenil: una práctica social y corporal en tiempos de la resignificación de la identidad juvenil chilena. Revista Brasileira de Ciências do Esporte, Campinas, v. 28, n. 1, p.39-53, set. 2006.

\footnotetext{
${ }^{17}$ As práticas corporais não são linguagens significativas. Wilson (2016) mostra como a ideia do "jeito certo de jogar" às vezes trava a evolução no futebol. Os episódios por vezes se combinam em crenças que estabelecem mudanças no status quo sobre o jeito de jogar. A história se sedimenta porque faz a união entre uma forma de jogar e a expectativa do público ("cair no gosto do público local"). O autor tematiza a evolução dos sistemas táticos e explora a relação entre este processo e as culturas locais. A legitimação de um determinado sistema leva à ideia de que é "o único legítimo" e por fim ele acaba se esgotando. O que significa que passa a não ser mais efetivo no jogo de futebol. A endogenia acaba por inviabilizar o determinado sistema. As práticas corporais são formas de dar vazão às coisas tal qual elas são; o aspecto moral mostra o que elas são quando são significativas, conformam o homem em si mesmo e daí não interessam para a EF porque rompem com a possibilidade da formação. A invenção da função do líbero no futebol italiano por Arrigo Sacchi dá disto testemunha: "Foi o sucesso do Milan na Europa, nos anos 1960, que introduziu o líbero como o padrão italiano. Um quarto de século depois, foi o sucesso do Milan na Europa que acabou com ele" (WILSON, 2016, p. 333). Sacchi explica que teve que romper com a característica de ênfase defensiva do futebol italiano que vinha da história da Itália, que sempre foram invadidos por todo mundo. "Ideia reforçada pela derrota esmagadora na Segunda Guerra mundial".
} 
BRACHT, Valter. A constituição das teorias pedagógicas da Educação Física. Caderno Cedes, Campinas, n. 48, p.69-88, ago. 1999.

COLETIVO DE AUTORES. Metodologia do ensino da Educação Física. São Paulo: Cortez, 2012.

GONZÁLEZ, Fernando Jaime; FENSTERSEIFER, Paulo Evaldo. Entre o "não mais" e o "ainda não": pensando saídas do "não-lugar" da EF Escolar I. Cadernos de Formação RBCE, Campinas, v. 1, n. 1, p.9-24, set. 2009.

GONZÁLEZ, Fernando Jaime; FENSTERSEIFER, Paulo Evaldo. Entre o "não mais" e o "ainda não": pensando saídas do "não lugar" da EF Escolar II. Cadernos de Formação RBCE, Campinas, v. 1, n. 2, p.10-21, mar. 2010.

KUNZ, Elenor. Transformação didático-pedagógica do esporte. Ijuí: Unijuí, 2006.

WACQUANT, Loïc. Corpo e Alma: notas etnográficas de um aprendiz de boxe. Rio de Janeiro: Relume Dumará, 2002.

WILSON, Jonathan. A pirâmide invertida: a história da tática no futebol. Campinas: Grande Área, 2016.

WISNIK, José Miguel. Veneno remédio: o futebol e o Brasil. São Paulo: Companhia das Letras, 2008.

\section{NOTAS DE AUTOR}

\section{AGRADECIMENTOS}

Não se aplica.

\section{CONTRIBUIÇÃO DE AUTORIA}

Não se aplica.

FINANCIAMENTO

Não se aplica.

\section{CONSENTIMENTO DE USO DE IMAGEM}

Não se aplica.

\section{APROVAÇÃO DE COMITÊ DE ÉTICA EM PESQUISA}

Não se aplica.

\section{CONFLITO DE INTERESSES}

Não se aplica. 


\section{LICENÇA DE USO}

Os autores cedem à Motrivivência - ISSN 2175-8042 os direitos exclusivos de primeira publicação, com o trabalho simultaneamente licenciado sob a Licença Creative Commons Attribution Non-Comercial ShareAlike (CC BY-NC SA) 4.0 International. Esta licença permite que terceiros remixem, adaptem e criem a partir do trabalho publicado, desde que para fins não comerciais, atribuindo o devido crédito de autoria e publicação inicial neste periódico desde que adotem a mesma licença, compartilhar igual. Os autores têm autorização para assumir contratos adicionais separadamente, para distribuição não exclusiva da versão do trabalho publicada neste periódico (ex.: publicar em repositório institucional, em site pessoal, publicar uma tradução, ou como capítulo de livro), com reconhecimento de autoria e publicação inicial neste periódico, desde que para fins não comerciais e compartilhar com a mesma licença.

\section{PUBLISHER}

Universidade Federal de Santa Catarina. Programa de Pós-Graduação em Educação Física. LaboMídia - Laboratório e Observatório da Mídia Esportiva. Publicado no Portal de Periódicos

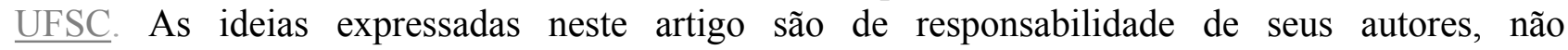
representando, necessariamente, a opinião dos editores ou da universidade.

\section{EDITORES}

Mauricio Roberto da Silva, Giovani De Lorenzi Pires, Rogério Santos Pereira.

\section{HISTÓRICO}

Recebido em: 25 de Março de 2019.

Aprovado em: 05 de Julho de 2019. 